\title{
Family Empowerment and Supportive Group in Handling Sexual and Gender Identity Disorder
}

\author{
Rika Damayanti \\ line 1 (of Affiliation): dept. name of organization \\ Universitas Pendidikan Indonesia \\ Bandung, Indonesia \\ r1k4.damayanti@student.upi.edu
}

\begin{abstract}
The phenomenon of Sexual and Gender Identity Disorder familiarly known as Lesbian, Gay, Bisexual and Transgender (LGBT) nowadays has become a very hot issue. People who are in favor of or against of it come up with their convincing arguments. Above all, providing proper help for those who are suffering from this disorder is much more urgent considering that most of the sufferers are the young people who are supposed to be the nation's future generation. Being exposed to such intense resistance including that of self, family and environment may bring about the sufferer's declining quality of life such as self-esteem problem, self-isolation, and even worse, severe psychological problem like a spur to commit suicide. Family empowerment through the optimization of five family tasks is very helpful for the family members. Continuous support from groups of caring individuals can gradually resolve the problem wisely and comprehensively.
\end{abstract}

Keywords-Family empowerment, supportive group, sexual disorder and gender identity

\section{INTRODUCTION}

Gender Identity is how someone takes him/herself as male or female in accordance with the normal condition of anatomy of gender, while Gender Identity Disorder is a conflict within individuals between the identity and the anatomy of gender. [1]. Another idea of Gender Identity Disorder commonly known as Lesbian, Gay, Bisexual and Transgender (LGBT) is the desire to possess a certain kind of gender opposite to the fact (female wishing to be male, or vice versa); or a belief that someone is occupying a body with the wrong gender.

This phenomenon has become a very hot issue lately. It has become a trending topic in social media as well as mass media both electronic and printed media. Many experts with various kinds of expertise have been invited by some TV stations to discuss this matter from different perspectives. Some others pour down their ideas through printed media or social media.

The arguments upon this controversial issue are very interesting to follow since both sides put forward convincing and solid ideas. The in favor group keeps striving for the existence of LGBT community for the sake of human rights endorsement, whereas the against group is trying hard to make the community members aware of their deviated behavior in terms of religious and cultural values.
In the early of 1970 , the term of homophobia emerged in US to designate the horrible fear for the gays and lesbians. The homophobic believed that the community of gays and lesbians tended to commit child abuse, be unable to be good parents, and hold the responsibility of the AIDS epidemic. Furthermore, they did act of violence, verbally and non-verbally, and even vandalized the gays. [1]

This problem should not be ignored. It needs a quick and accurate response because the sufferers are apt to undergo mental disorder due to self-conflict and negative stigma from others for being discrete from the Indonesian typical characteristics basing upon the religious and cultural values. To confront them violently is not an option at all. It requires a comprehensive effort including promoting, preventive, curative and rehabilitative one.

The community of LGBT in Indonesia is really worrying because they openly declare their existence in the middle of the society. Let us take some examples: the same sex marriage in Bali, the special android application for LGBT community members, a college student treated at a mental hospital for being stressful due to pressure from family and environment to respond his being a gay. The latest one, news on September 1 , 2016 , it was found a gay android application which involved under-age children.

Family plays an important role in avoiding and handling the family member's health problems, physically and psychologically, including sexual and gender identity disorder. There are five prominent task of a family regarding health: the family is able to recognize the health problems of the members, the family is able to make decisions, the family is able to do the treatment, the family is able to modify the family environment, and the family is able to make good use of the health service facilities to treat the family members.

Supportive Group is an alternative of group therapy generally used to cope with various kinds of mental disorder. Through it, each member who has a problem is given a chance to share it to others and receives support from others to solve it. This practice is carried out anywhere and anytime upon the group members' approval, so the continuity and sustainability of the supportive group can be realized.

Therefore, the writer is trying to describe how supportive group and family empowerment may become the solution to handle sexual and gender identity disorder. 


\section{REVIEW OF LITERATURE}

\section{A. Gender Identity Disorder}

Gender Identity Disorder is the desire to possess a certain kind of gender opposite to the fact (female wishing to be male, or vice versa); or a belief that someone is occupying a body with the wrong gender. Another opinion is stating that Gender Identity Disorder is a conflict within individuals between the identity and the anatomy of gender.

\section{B. The Causes of Gender Identity Disorder}

\section{1) Biological Factor}

Gender Identity Disorder, in spite of the varied issues, is doubtfully influenced by the physical disorder. It is specifically affected by hormones. Man body produces testosterone hormone which has an effect on brain neurons, and further contributes to brain masculinity in the area of hypothalamus; it goes the same way to the hormone of feminism.

\section{Social and Psychological Factor}

In Psycho-social approach, the formation of Gender Identity Disorder is mainly affected by the interaction of child personality, and the quality and attitude of parents. Culturally, boys are not allowed to show feminine behaviors, and vice versa. There is also a sharp distinction of clothes and toys for boys and girls.

\section{Treatment of Sexual and Gender Identity Disorder}

Providing treatment for the sufferers of sexual and gender identity disorder is not easy since not all of the sufferers can openly tell their problem. It happens due to the negative stigma labeled to them by the society that considers them against the values of religion and culture held by Indonesian people. Family as the first and the main nurturing place for children can be the source of strength for them in the healing process. Family should be able to explore the potency of the family member who is in trouble to ease the treatment process. Besides, family should also explore the potency of other family members to provide help in giving the treatment.

\section{E. Family Empowerment}

A powered family is the condition in which every family member is capable of performing his/her own role, function, and task, not only focusing on father and mother, but all family members are involved in the family activities suited with his/her growing stage. There are five tasks of the family in the field of health:

1. Knowing the problems of the family members

2. Making a right decision in giving treatment and communicating to other family members to get involved in making decision to give treatment for the troubled family member.

3. Taking care of the troubled family member, for this purpose family should also have the adequate knowledge and skills to solve the family member's health problem either physically and psychologically.
4. Maintaining the living environment to support the health condition of the family members. .

5. Making good use of the health service and health facilities. If a family member shows health problems or symptoms of sexual deviation, family should make sure that the troubled family member gets an immediate treatment.

The implementation of those five tasks is influenced by such factors as stage of family development, physical and emotional family condition, family economic status, family cultural, ethical and spiritual values, available resources in the family and the environment, and the characteristics of agebased growing and developing stage [9].

\section{F. Supportive Group}

Supportive group is a group of people who directly plan, manage and respond specific or disadvantageous issues and pressures. The main purpose of its establishment is to provide support and solve the problem faced by its members [8]. The primary aim of forming supportive group is to furnish assistance, set the focus of healing process, and do social action. The purpose and expectation in the group is to share positive experience among group members. In short, solving the problem immediately, giving motivation and creating individual behavioral change are, among others, the important purpose of setting up supportive group.

The following are the five-steps of supportive group: Step I: Recognizing Problem, Step II: Ways to Solve the Problem, Step III: Selecting Solution, Step IV: Doing Action to Solve the Problem. Step V: Preventing of Relapses.

\section{IMPLEMENTATION}

It is the execution of the supportive group activities which is carried out as a means to sustain the existence of the supportive group and assure that the aim of supportive group is accomplished. The following are the activities included: arranging the schedule of the programs, deciding the topics to be discussed in each session, selecting the leader of discussion (the leader is one of the group members and each member has a chance to be the leader), carrying out the five-steps of supportive group activity started with opening, action and closing, taking notes of the group's capabilities, and evaluating the group performance.

\section{DISCUSSION}

Sexual and gender identity disorder does not occur all of a sudden and is not caused by a single factor, but multi-causal factors, instead including internal and external factors. Family as the closest party to the family member who is having a problem should be able to be the first one who handles the problem. Family empowerment through the five tasks of family in the health field can optimally help the family identify the problems appearing in the family. Sexual and gender identity disorder is affecting individual's behavioral and social change, so that family can easily recognize the problem to prevent worse condition. Family can immediately decide to take the troubled family member to the professional and competent persons to get some help by involving the whole family members to give the treatment psychological support. 
Further, by not judging and giving punishment can help the troubled family member improve his/her self-esteem and selfconfidence to solve his/her problem.

Family should also learn to modify the nurturing pattern, communication pattern and child's environment to assist the curing process and, take him/her to get health service if the sexual disorder is related to biological factor which requires varied health checks and hormonal therapy, or even surgical treatment. Family should be available to share problems faced by family members due to pressures and internal and external conflict. Family empowerment should last continuously, before and whilst the problem happens and after recovery.

Next, supportive group can provide continuous support. Through routine sharing sessions, problems faced by each member can be gradually resolved. If necessary, group may ask for help from the professional individuals like nurse, doctor, psychologist, psychiatrist or religious figures to help them solve the problems in line with their respective expertise.

\section{CONCLUSION AND SUGGESTION}

1. Sexual and gender identity disorder does not belong to a certain individual or family only but also to the whole society because it is closely related to religious norms and cultural values held by the society.

2. Providing assistance to help the treatment is far more important than arguing about the pros and cons of this problem since most of the sufferers are the young generation who someday will be the next leaders of the nation.

3. Family plays an important role in the process of treating the troubled family member. Family empowerment through the optimizing of the five tasks of family in the field of health is very helpful for the family members.

4. Supportive group comprising caring individuals with their gradual but continuous effort provides a lot of help to solve the problems comprehensively.

\section{BIBLIOGRAPHY}

[1] Nevid, Rathus, Greene, "Psikologi Abnormal", edisi kelima, jilid 2, alih bahasa Tim Fak Psikologi UI, Jakarta, Erlangga, 2005

[2] Stuart "Psychiatric Nursing", St. Louis, Missouri, Mosby Inc, 2009

[3] Townsend, "Psychiatric Mental Health Nursing", F. A Davis Company, Philadelphia, 2009

[4] Varcarolis "Essentials of Psychiatric Mental Health Nursing", St. Louis Saunders, Elsevier Inc, 2013

[5] Appelbaum, A.H. Supportive Therapy, 4, http://www.focus. psychiatryonline.org/cgi. 1995

[6] Chien, W.T., Chan, S.W.C., dan Thompson, D.R. 12 , http://bjp.rcpsych.org/cgi. 2006

[7] Holmes, J. Supportive Psychotherapy The Search For Positive Meanings. 1, http://www.bjp.rcpsych.org/cgi. 1995

[8] Hunt. A Resource Kit for Self Help / Support Groups for People Affected by an Eating Disorder. http://www.medhelp.org/njgroups/ VolunteerGuide.pdf. 2004.

[9] Friedman, Marilyn. Keperawatan Keluarga Teori dan Praktik, Ed.3. Jakarta. EGC.1998 